\title{
LAS INFECCIONES NOSOCOMIALES COMO UN NUEVO EVENTO DE RESPONSABILIDAD OBJETIVA EN EL SISTEMA COLOMBIANO. REFLEXIÓN SOBRE SU FUNDAMENTO A PARTIR DE LA EXPERIENCIA FRANCESA
}

\author{
NOSOCOMIAL INFECTIONS AS A NEW EVENT OF STRICT LIABILITY \\ IN THE COLOMBIAN SYSTEM. REFLECTION ON ITS LEGAL MERITS \\ FROM THE FRENCH EXPERIENCE.
}

\section{Mónica L. Fernández M.*}

\begin{abstract}
RESUMEN: Este artículo aborda el problema de la indemnización de los daños derivados de infecciones nosocomiales. Con base en el método de la investigación teórica, luego de una revisión de la estructura y contenido de los sistemas francés y colombiano, la autora concluye que Colombia no está aun preparada para avanzar hacia el sistema de responsabilidad objetiva que actualmente propone la jurisprudencia de este país.
\end{abstract}

Palabras clave: Infecciones nosocomiales, responsabilidad, indemnización, falla del servicio, fondo de garantía.

ABSTRACT: This article discusses, from a comparative law perspective, the problem of compensation for damage caused by nosocomial infections. Based on the method of theoretical research, following a review of the structure and content of the French and Colombian systems, the author concludes that Colombia is not yet prepared to move towards strict liability system currently proposed by the jurisprudence of this country.

Key words: Nosocomial infections, liability, compensation, service failure, the guarantee fund.

\section{INTRODUCCIÓN}

El Consejo de Estado colombiano, mediante fallo del pasado 29 de agosto de 2013 (expediente 30283), declaró la responsabilidad objetiva del antes Instituto de Seguros Sociales (ISS), por el perjuicio ocasionado a un menor de edad ( 9 meses a la época de la hospitalización) consistente en un daño cerebral con secuelas neurológicas irreversibles (en-

Ph.D. en Persona y Tutelas Jurídicas por la Scuola Superiore di Studi Universitari e di Perfezionamento Sant'Anna di Pisa (Italia). Investigadora visitante en la Universidad de Paris I Panthéon-Sorbonne (Francia). Abogada de la Universidad del Cauca (Colombia). Especialista en Responsabilidad y Daño Resarcible de la Universidad Externado de Colombia y en Docencia Universitaria de la Universidad Militar. Tratadista, conferencista, investigadora y docente universitaria. Calle 160 No.72-51 Bogotá. tutorias.mfernandez@gmail.com.

Este artículo corresponde al resultado de una investigación adelantada en el marco del Proyecto denominado "La responsabilidad de las entidades de salud en Colombia", desarrollado dentro de la línea de investigación "Derecho Privado" perteneciente al Grupo de investigaciones "Derecho Privado y del Proceso" de la Facultad de Derecho de la Universidad Libre de Colombia. El proyecto de investigación en mención ha sido financiado por la citada Universidad. 
fermedad motriz cerebral, cuadriplejia mixta -predominio izquierdo-, regresión en el desarrollo psicomotor), causado como consecuencia de una meningitis bacteriana que el menor paciente adquirió y desarrolló mientras estuvo internado en la Clínica Jorge Bejarano del ISS $^{1}$.

En la citada sentencia, el Consejo de Estado concluyó que se trataba de un daño que encontraba su origen en una infección nosocomial u hospitalaria, para cuya definición trajo a referencia aquella dada por la Organización Mundial de la Salud (OMS), en los siguientes términos: "Una infección contraída en el hospital por un paciente internado por una razón distinta de esa infección. Una infección que se presenta en un paciente internado en un hospital o en otro establecimiento de atención de salud en quien la infección no se había manifestado ni estaba en período de incubación en el momento del internado. Comprende las infecciones contraídas en el hospital, pero manifiestas después del alta hospitalaria y también las infecciones ocupacionales del personal del establecimiento"2.

Luego de concluir que en el caso concreto no podía imputarse responsabilidad con fundamento en el régimen de falla (culpa) del servicio, dado que según su parecer no existía evidencia científica que corroborara que dicha falla era la causa de la infección bacteriana que afectó al paciente, es decir, el sistema de falla probada no se encontraba establecido y el de falla presunta había sido abandonado por la Consejo de Estado en este ámbito, y que además la materia de infecciones nosocomiales no podía considerarse como un "evento adverso" porque así lo había establecido la misma Corporación desde hace varios años ${ }^{3}$, el Consejo de Estado fundamentó finalmente la declaratoria de responsabilidad en la teoría del "riesgo-álea", cambiando la tendencia por el reconocimiento de una responsabilidad de corte subjetivo en el campo de la prestación del servicio médico-hospitalario.

Así, luego de reconocer que la Corporación "no se ha ocupado de desarrollar una dogmática específica aplicable a los casos de daños derivados de infecciones nosocomiales en los que no existe falla probada del servicio" ${ }^{4}$, concluye que "sí ha trazado unas primeras pautas para afirmar, en consonancia con la tendencia que impera en el derecho comparado, que estos deben ser analizados desde un régimen objetivo de responsabilidad, que en nuestro caso sería el de riesgo excepcional". Es decir, el Consejo de Estado concluye que para el caso específico de los perjuicios derivados de infecciones nosocomiales, cuando no se demuestre la falla del servicio, en lugar de exonerar de responsabilidad al ente demandado, se la atribuye por el solo hecho de que esté demostrado que la infección se produjo por una bacteria de carácter intrahospitalario, pues ello basta para imputar responsabilidad a la entidad bajo un título de atribución de carácter objetivo.

Dentro de los fundamentos que cita la Corporación y que le sirven de sustento a su decisión, está la mención del sistema francés, respecto del cual, el Consejo de Estado recalca como "en el marco de este sistema, los establecimientos y profesionales de la salud,

\footnotetext{
1 Si bien es cierto, el sentido de esta decisión venía siendo tímidamente aceptada por la Corporación, la misma ha venido siendo replicada con abierta aceptación en fallos sucesivos. Ver Consejo de Estado 11 junio 2014 Exp. 27089 y 10 septiembre de 2014 Exp. 27771

2 Organización Mundial de la Salud -OMS- (2003).

3 Consejo de Estado. Sección Tercera. 24 de marzo de 2001, Exp. 20836 y 19 de agosto de 2009, Exp. 17733

4 Consejo de Estado. Sección Tercera. Agosto 29 de 2013. Exp. 30283.
} 
sean de carácter público o privado, responden por los daños resultantes de infecciones hospitalarias, salvo si ellos logran demostrar que la infección fue causada por un factor ajeno al servicio sanitario"'5; es decir, se apoya en el sistema objetivo que respecto a las infecciones nosocomiales rige actualmente en Francia.

Sin embargo, se considera que dicha argumentación está lejos de corresponder al contexto que hoy rige en dicho país y en cuyo análisis se centrará esta reflexión; en consecuencia, el fundamento de la comparación que le sirvió de sustento al Consejo de Estado para atribuir responsabilidad objetiva al ente demandado no es certero. En efecto, como se verá más adelante, el sistema de indemnización de daños por infecciones nosocomiales que se encuentra vigente en Francia, no le sirve de argumento para la construcción de un sistema de responsabilidad objetiva como el que hoy pretende instaurar la jurisprudencia colombiana.

Así pues, con el fin de desatar el litigio que motivó la citada sentencia del 29 agosto 2013, el Consejo de Estado consideró que ninguna culpa había sido cometida por la entidad demandada, sin embargo, dada la existencia de un daño evidente, se consideró que había responsabilidad objetiva con fundamento en la teoría del riesgo excepcional, el cual "deriva su existencia de la consideración según la cual el sujeto de derecho que despliega una actividad cuya realización implica el riesgo de ocasionar daños, debe asumir la responsabilidad derivada de la causación de estos en el evento en que sobrevengan o de que, aun cuando la actividad no entrañe verdadera peligrosidad, conlleva la asunción de las consecuencias desfavorables que su ejercicio pueda producir, por parte de la persona que de dicha actividad se beneficia"' .

Si bien el Consejo de Estado no analizó la falla del servicio médico, pues no indagó que la entidad hubiera incumplido las normas y protocolos existentes para el manejo y control de las infecciones nosocomiales, lo cual hubiera sido lo más razonable, y concluyó simplemente que había responsabilidad objetiva con fundamento en la teoría del riesgo excepcional, un análisis detenido del asunto permite evidenciar la preocupación de fondo de la Corporación, por la solución de aquellos eventos donde no obstante la diligencia médica, se generan daños a los pacientes, es decir, lo que en derecho comparado se conoce como "alea terapéutica"

En este orden de ideas, el Consejo al encuadrar las infecciones nosocomiales dentro del marco de la responsabilidad objetiva, no solo demuestra falencias axiológicas en el manejo de la figura ${ }^{8}$, sino que además, una decisión en tal sentido genera un impacto negativo importante en el contexto colombiano, no solo en el campo de la salud, sino también, en la economía y en la sociedad en general.

Todo ello se explica por un hecho y es el de no existir en Colombia un marco normativo que sustente el paso hacia una responsabilidad de corte objetivo en este campo, tal como sucede en Francia por ejemplo, donde dicho régimen se apoya en la existencia de una

\footnotetext{
Consejo de Estado. Sección Tercera. Agosto 29 de 2013. Exp. 30283.

6 Consejo de Estado. Sección Tercera. 26 de marzo de 2008, Exp. 16530.

FERnándeZ (2008) p. 371 y ss.

8 TAMayo (2014) p. 21.
} 
garantía del tipo aseguramiento obligatorio de la responsabilidad y la existencia de un fondo de garantía que asume este tipo de indemnizaciones en la mayoría de los casos, opciones ambas que se duda mucho puedan implementarse en un futuro cercano en Colombia.

Es decir, entra en tela de juicio la validez material de esta regla, en tanto, se duda que esta nueva postura sirva realmente para resolver los conflictos que se generan en materia de daños derivados de infecciones intrahospitalarias. Al contrario, se considera que este nuevo postulado, no se adecua a la realidad social que intenta regular, pues no se entiende hasta qué punto una responsabilidad objetiva pueda dar una solución a la necesidad que plantea el fenómeno, es decir, indemnizar a las víctimas de infecciones nosocomiales en ausencia de negligencia médica. Si bien no se discute el fin que se persigue con este nuevo postulado, no se comparten los medios utilizados para el efecto, dada la realidad en el contexto colombiano.

Así pues, en el marco del problema de investigación que acaba de esbozarse, dado que resulta necesario determinar si es adecuado, conveniente u oportuno implementar un sistema de responsabilidad objetiva de las entidades de salud, para resolver la problemática que genera la causación de daños por infecciones intrahospitalarias cuando no está de por medio una conducta negligente suficientemente demostrada, las preguntas que sustentaron esta investigación son las siguientes: ¿Existe en Colombia un marco jurídico adecuado para transitar hacia un régimen objetivo de responsabilidad para las entidades de salud en materia de infecciones nosocomiales? y ¿Qué alternativas jurídicas, en consonancia con el derecho francés y acordes con la realidad colombiana, se podrían proponer para solucionar estos eventos de daños nosocomiales causados por culpa o sin ella?

La respuesta a estas preguntas implica reconocer, en primera instancia, la necesidad de que Colombia comience a avanzar hacia otro estadio de la discusión, hacia un problema de otra amplitud: la presencia real de daños en ausencia de culpa médica, es decir, el "alea terapéutica”, ámbito en el cual, Francia nos lleva más de 70 años de ventaja9 .

En suma, el fin último de la investigación, es el de identificar los fundamentos teórico-normativos que permitan proponer la construcción de un sistema de responsabilidad de las entidades públicas de salud por daños derivados de infecciones nosocomiales, que resulte congruente con la realidad actual de Colombia.

El proceso investigativo desarrollado se enmarca, esencialmente, dentro del enfoque cualitativo e igualmente ha sido sustentado en la posición epistemológico-metodológica hermenéutico-interpretativa, a través del empleo de métodos propios de dicho paradigma, esto es, el método hermenéutico y la investigación teórica, los cuales se han desarrollado esencialmente a través de la técnica de indagación documental, aplicando el análisis, la síntesis, la inducción y la deducción como métodos generales, combinados con otros métodos particulares como la comparación, la abstracción, la conceptualización y con un alcance exploratorio, descriptivo, analítico y comparativo. Igualmente, mediante el proceso de muestreo por conveniencia, se obtuvo apoyo en la opinión que, a través de entrevistas, se pudo lograr gracias a la participación de los siguientes integrantes del sector salud, a quienes se agradece los aportes al desarrollo de esta investigación: Dr. Andrés Castro

9 Fernández (2008) p. 369; Fernández (2008a) p. 15. 
García, Secretario General y Jurídico del Hospital San Ignacio de Bogotá; Dr. Juan Carlos López, Presidente de Salud Vida EPS; Dr. Luis Alberto Sabogal Aguilar, Director Nacional de Salud de Salud Vida EPS; y Dra. María de los Ángeles Meza, Directora Nacional de Demandas de Salud Total EPS en Bogotá ${ }^{10}$.

\section{EL FACTOR OBJETIVO DE IMPUTACIÓN EVIDENCIA UNA FALTA DE CLARIDAD CONCEPTUAL}

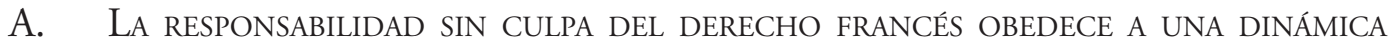 AUSENTE EN COLOMBIA \\ Las infecciones nosocomiales o intrahospitalarias, entendidas como "toda infec-} ción que aparece en el curso o como consecuencia de una hospitalización y que no estaba presente al momento de la puesta en marcha del acto generador ni al momento de la admisión"11, son de dos (2) clases: Endógenas y exógenas ${ }^{12}$. Las endógenas, son aquellas donde el enfermo se contamina por sus propios gérmenes, interviniendo en este caso la situación médica del paciente, es decir, su edad y su patología, sus tratamientos, la calidad de los cuidados médicos y la presencia de gérmenes patógenos para ciertos pacientes debilitados. Por su parte, las infecciones exógenas, pueden ser también de tres tipos, a saber: aquellas que se transmiten de un paciente a otro, aquellas provocadas por los gérmenes del personal portador de los virus y las infecciones ligadas a la contaminación del medio ambiente hospitalario.

De este modo, las infecciones nosocomiales pueden ser de origen exógeno o endógeno $^{13}$. Son de origen exógeno, cuando tienen por causa gérmenes exteriores al paciente, es decir, microbios provenientes de condiciones como el agua, aire, locales y alimentación, del material utilizado, del personal médico o paramédico, o de otro paciente. Y son de origen endógeno cuando el paciente se infecta con sus propios microbios, con ocasión de un acto invasivo o en razón de la precariedad de su estado de salud. Todas estas infecciones pueden ser debidas a bacterias, hongos, parásitos y virus ${ }^{14}$.

Según la Academia de Medicina francesa, las infecciones nosocomiales exógenas son aquellas causadas por microorganismos del medio ambiente que se introducen en el cuerpo del enfermo, a través de un vector animado o inanimado y se transmite más a menudo a través de otros enfermos. Las infecciones endógenas, en cambio, son aquellas que provienen del mismo enfermo, en cuyo organismo la vía digestiva (desde la boca hasta el ano), la piel y la vagina son los reservorios humanos más importantes y a partir de los cuales se produce la infección ${ }^{15}$. Además, según el origen de los gérmenes, se pueden distinguir dos

\footnotetext{
10 Todos representantes de estas Entidades Promotoras de Salud (EPS) e Institución Prestadora del Servicio de Salud (IPS) de connotado renombre en Colombia, responsables de la afiliación al Sistema de Salud y de la prestación del servicio mismo.

11 Castelletta (2002) p. 162.

12 Gibert (2011) p. 409.

13 WeLSH (2003) p. 286.

14 Dorsner-Dolivet (2006) p. 194.

15 LANGlois (2002) p. 2. Las definiciones aquí dadas corresponden a una traducción libre de la autora.
} 
clases de infecciones nosocomiales: las infecciones primarias, que corresponden a aquellas donde los gérmenes están presentes en el cuerpo del enfermo al momento de su admisión (incluso si son portadores sanos) y las infecciones secundarias, que resultan de una contaminación por gérmenes verdaderamente hospitalarios (contaminación principalmente a nivel de la piel y del tracto digestivo) y que pueden conducir a una infección declarada después de la realización de un acto médico, a menudo invasivo, y/o porque hay déficit inmunológico del sujeto.

La ocurrencia de estas infecciones dio lugar en Francia a una serie de decisiones judiciales que se mostraban cada vez más favorables a los pacientes y sus soluciones fueron consagradas en su mayoría a través de la Ley n.303 del 4 marzo de 2002, conocida como la ley Kouchner, tendiente a regular los derechos de los pacientes y la calidad del sistema de salud. Una ley que focaliza la exigencia pública sobre la seguridad médica y sanitaria debida a los pacientes y que realiza una unificación del derecho de la responsabilidad médica y de la indemnización de las víctimas de accidentes médicos, que estaba ya anunciada por la armonización jurisprudencial de los dos órdenes jurisdiccionales

Así, en una primera etapa, la jurisprudencia francesa se había negado a someter a un régimen específico la materia relativa a las infecciones nosocomiales, pues consideraba que la responsabilidad del médico en este aspecto, estaba subordinada a la prueba de una culpa $^{16}$. Pero, las dificultades de prueba a las cuales se enfrentaban a menudo estas víctimas, condujo poco a poco a que la jurisprudencia, considerara una presunción de culpa, la cual rápidamente, cedió su lugar a una presunción de responsabilidad.

El derecho francés ha sufrido un largo itinerario en su intención de regular la indemnización de los daños derivados de aquellas infecciones adquiridas en el ámbito hospitalario, el cual se concreta en una combinación de regímenes subjetivo (prueba de la culpa del profesional) y objetivo de responsabilidad (presunción de responsabilidad o responsabilidad de pleno derecho de los establecimientos hospitalarios). De este modo, de acuerdo con el derecho positivo aplicable en Francia, en los casos de infecciones nosocomiales, el profesional de la salud responde solo en caso que su culpa quede comprometida; por su parte, el establecimiento de salud a través de su seguro responde según un régimen de objetivo, pero solo cuando el umbral de incapacidad permanente generada por la infección está por debajo del 25\%, pues en aquellos casos donde la incapacidad permanente supera ese umbral, interviene la Solidaridad Nacional, a través del Fondo de Garantía ONIAM (Office National d'Indemnisation des Accidents Médicaux, des Affections Iatrogènes e des Infections Nosocomiales).

Empero, un hecho no tiene discusión y es que la víctima o la parte que lo invoque debe, en todos los casos, demostrar el carácter nosocomial de la infección ${ }^{17}$ y para ello, la prueba pericial cobra una importancia capital, donde los expertos se apoyan en una presunción temporal, que facilita la prueba dejada a cargo de la víctima y que está relacionada con el momento de aparición de la infección y con la existencia o no de actividades contra-

\footnotetext{
16 Cass. 1 re civ. 9 déc. 1986 , n. 84-15753.

17 Gibert (2011) p. 413; Hocquet-Berg (2013) p. 5.
} 
indicadas que favorezcan dicha infección. No obstante, esta presunción admite prueba en contrario, en atención al plazo de incubación o la resistencia del germen.

En este orden de ideas, se aplica un régimen de presunción temporal para establecer si la infección tienen o no un carácter nosocomial ${ }^{18}$ y en tal sentido, la infección se considera nosocomial si aparece al menos 48 horas después del ingreso o inicio de la hospitalización o 72 horas después de terminada la hospitalización. Sin embargo, es de anotar que alguna doctrina, considera que este concepto clásico ha ido cambiando a medida que se ha ido profundizando en el estudio de estas infecciones; así, se indica que en el año 1994 el Centro para el Control y la Prevención de las Enfermedades (Center for Disease Control and Prevention), CDC de Atlanta, redefinió el concepto de infecciones intrahospitalarias, señalando que, con pocas excepciones, no existe un tiempo específico durante o después de la hospitalización para determinar si una infección debe ser confirmada como nosocomial, pues para determinar este aspecto habría que analizar el criterio clínico complementado por los hallazgos microbiológicos concretos ${ }^{19}$.

Por otra parte, para las infecciones de las heridas operatorias se estiman como nosocomiales aquellas producidas dentro de los 30 días siguientes a la intervención y si se trata de un proceso de introducción de una prótesis o de un implante, se estiman como nosocomiales las infecciones producidas dentro del año siguiente a la intervención ${ }^{20}$.

En Francia, la noción de infección nosocomial contenida en la Circular ministerial n. 263 del 13 octubre 1988, señalaba que ésta consiste en "toda enfermedad provocada por microorganismos: contraída dentro de un establecimiento de salud por un paciente, luego de su admisión, sea para su hospitalización, sea para recibir atención ambulatoria; cuyos síntomas aparecen durante su estadía o después; se requiere que la infección sea reconocida desde los planos clínico y microbiológico" ${ }^{21}$; sin embargo, esta definición fue reemplazada por la de la Circular n. 3058C del 29 diciembre 2000, que la define escuetamente así: "infección contraída dentro de un establecimiento de salud", al parecer atendiendo al origen de la palabra "nosocomial" que proviene del griego nosokomein que significa 'nosocomio' u 'hospital' y que a su vez deriva de las palabras griegas nosos, enfermedad y komein, cuidar, o sea 'donde se cuidan los enfermos', en consecuencia, la infección nosocomial es, sin más, aquella asociada con un hospital o institución de salud ${ }^{22}$.

Como antes se indicó, la jurisprudencia francesa se movió dentro de una serie de decisiones judiciales que se mostraron cada vez más favorables a los pacientes víctimas de infecciones nosocomiales, en razón a la dificultad probatoria a la que se enfrentaban en este tipo de procesos. El itinerario jurisprudencial inició con una primera etapa donde se exigía la necesidad de demostrar la culpa, posteriormente se dio paso a una etapa que consideraba una presunción de culpa y finalmente, la consagración de una presunción de responsabilidad.

18 Gibert (2011) p. 414.

19 Nodarse (2002) p. 203.

20 Hocquet-Berg (2012) p. 3.

21 Circ. Ministre de la solidarité, de la santé et de la protection sociale Nº 88-263, 13 oct. 1988.

22 Nodarse (2002) p. 201. 
En lo que respecta a la presunción de responsabilidad, fue la jurisdicción ordinaria la que dio el primer paso hacia su reconocimiento. Mediante tres (3) fallos emitidos el 29 de junio de 1999, la Casación dio una nueva orientación a su jurisprudencia. Los citados tres (3) fallos que tuvieron por objeto la declaratoria de responsabilidad debido a una infección por estafilococo dorado ${ }^{23}$, consideraron que en materia de infección nosocomial, la obligación de seguridad era una obligación de resultado y recaía sobre el establecimiento de salud y sobre el médico. En consecuencia, solo la prueba de una causa extraña permitía la exoneración de la responsabilidad del médico o del establecimiento.

Por su parte, el Consejo de Estado francés, mediante el fallo Cohen ${ }^{24}$, avanzó en su inicial consideración de un sistema de responsabilidad por culpa, señalando que la sola existencia de una infección nosocomial, revelaba una culpa o falla en la organización o funcionamiento del servicio hospitalario por no suministrar materiales y productos estériles, es decir, la corporación aplicó la presunción de culpa en materia de asepsia. En el año 1989 el fallo Bailly confirma esa decisión. Sin embargo, se considera que esta presunción de culpa, a la que se refiere el Consejo de Estado, es una verdadera presunción de responsabilidad ${ }^{25}$, ya que solo podría ser desvirtuada con la prueba de que el paciente fuese portador del germen infeccioso al entrar en el hospital, prueba del origen endógeno de la infección que es bastante difícil de aportar.

La ley Kouchner luego de reiterar el principio clásico de la responsabilidad médica fundamentada en la culpa, en razón a que la actividad médica sigue estando investida de una acción humana que no puede tolerar las fallas técnicas y éticas de la profesión ${ }^{26}$, señala, como excepción, que en materia de infecciones nosocomiales habrá responsabilidad, salvo que se demuestre el acaecimiento de una causa extraña (art. L 1142-1 I), es decir, en ausencia de una culpa probada, el alea nosocomial es institucionalmente reconocida.

La evolución jurisprudencial civil y contencioso administrativa en Francia, consagró así un régimen de responsabilidad objetiva aplicable a los establecimientos de salud en materia de infecciones nosocomiales. Este régimen inspiró, en gran parte, la citada Ley n. 303 del 4 marzo 2002 que renovó el sistema de indemnización para estas infecciones, organizando una responsabilidad sin culpa en caso de infección nosocomial, pero limitándola a aquellas infecciones que no son debidas a fuerza mayor. Sin embargo, apenas entrada en vigencia esta ley, fue objeto de modificación por la Ley n. 1577 del 30 diciembre del mismo año, al considerarse que con dicha responsabilidad objetiva, se corría el riesgo de encarecer considerablemente la carga financiera para las aseguradoras ${ }^{27}$.

Así, la evolución de la responsabilidad por infecciones nosocomiales en Francia, se estructura en distintos regímenes, dependiendo de la fecha de ocurrencia del acto médico,

\footnotetext{
23 Cass. 1 re civ., 29 juin 1999, n. 97-15.818, n. 97-21.903 y n. 97-14.254.

24 Conseil d'État, 9 déc. 1988 , n. 65087.

25 Lambert-Faivre (2004) p. 781.

26 LAMbert-Faivre (2004) p. 702.

27 Dorsner-Dolivet (2006) p. 200.
} 
generador del daño. El régimen actual en esta materia, es el resultado de una ruta que ha transcurrido el tema en dicho país, el cual se resume de la siguiente manera ${ }^{28}$ :

En cuanto a las infecciones nosocomiales imputables a un acto médico ocurrido antes del 5 septiembre 2001, se presentaron varias etapas. Respecto a aquellos ocurridos antes de 1988 (para los hospitales públicos) y antes de 1999 (para las clínicas privadas), la víctima de una infección nosocomial, que buscara el resarcimiento de los daños causados por dicha infección, tenía que demostrar la culpa de la entidad hospitalaria en el acaecimiento de dicha infección. Es decir, se trataba de un régimen de responsabilidad subjetiva fundamentado en la culpa o falla probada, la cual era difícil de establecer, ya que en la mayoría de los casos las reglas de asepsia eran (y aún lo son) ignoradas por la víctima.

En una segunda etapa, la Casación estableció una presunción simple de culpa imputable solo a la Clínica privada, respecto a las infecciones contraídas durante una intervención en sala de cirugías. Esta presunción era desvirtuable mediante la prueba de la ausencia de culpa, consistente en la simple demostración de haber respetado las normas de esterilización y asepsia vigentes.

Durante una tercera etapa, con ocasión de los citados tres fallos emitidos en al año 1999, la Casación dio un giro importante en la materia, al considerar que la prueba de la ausencia de culpa no era suficiente para exonerar de responsabilidad, consagrando de esta manera una obligación de seguridad de resultado, respecto de la cual solo cabía para exonerarse la demostración de la ocurrencia de una causa extraña.

Con relación a las infecciones nosocomiales imputables a un acto médico ocurrido entre el 5 septiembre 2001 y el 1 enero de 2003, la ley Kouchner consagra una responsabilidad de pleno derecho, reservada solo para los establecimientos de salud.

En efecto, el artículo L 1142-1, I del Código de la Salud Pública (Ley 303 de 2002), reconoce claramente la existencia de una responsabilidad sin culpa a cargo de los establecimientos de salud en materia de infecciones nosocomiales, salvo si aportan la prueba de una causa extraña. Es decir, los establecimientos de salud son responsables de los daños que resultan de las infecciones nosocomiales adquiridas dentro de ellos, salvo que demuestren la ocurrencia de una causa extraña exoneratoria de responsabilidad (fuerza mayor, culpa de la víctima o hecho de un tercero), que presente los caracteres de imprevisibilidad, irresistibilidad y exterioridad. De este modo, el régimen subjetivo de responsabilidad por culpa, queda reservado para los profesionales de la salud y en este caso, el paciente debe demostrar la culpa del profesional, a fin lograr comprometer su responsabilidad.

En cuanto al resarcimiento, la ley 303-2002 estableció que si el daño causado era superior al $24 \%$ de incapacidad permanente, o producía 6 meses de incapacidad temporal para el trabajo o problemas graves en las condiciones de existencia o una incapacidad definitiva para ejercer su profesión anterior, la infección nosocomial abría la posibilidad de la vía de arreglo amistoso ante las Comisiones Regionales de Conciliación y de Indemnización. 
Finalmente, respecto a las infecciones nosocomiales imputables a un acto médico ocurrido después del 1 enero 2003, se consagra un régimen de responsabilidad que varía según la gravedad del daño, así:

El artículo L 1142-1-1, 1 del mismo Código de Salud Pública, adicionado por el artículo 1 de la Ley 1577 de 2002, establece una reparación de pleno derecho a título de solidaridad nacional, en aquellos casos de daños que resulten de infecciones nosocomiales, que generen una tasa de incapacidad permanente superior a $25 \%$ y en los casos de muerte provocada por dichas infecciones.

Sin embargo, hay que tener en cuenta que en este caso, la ONIAM si bien asume la indemnización del daño de pleno derecho, cuenta con un recurso contra los profesionales y establecimientos de salud, en el caso que su culpa sea establecida, por incumplimiento de las obligaciones a su cargo relacionadas con la lucha contra las infecciones nosocomiales (Art. 1142-21 Ley 1577 de 2002), es decir, en este caso la responsabilidad solo se compromete en caso de culpa demostrada ${ }^{29}$.

En este orden de ideas, para los daños que causen una incapacidad permanente inferior o igual al $25 \%$ o para las infecciones nosocomiales que causen otra clase de perjuicios, que es la hipótesis más frecuente ${ }^{30}$, se aplican dos regímenes de responsabilidad, de la siguiente manera: Un régimen de presunción de responsabilidad para los establecimientos de salud, de la cual cabe exonerarse únicamente con la demostración de una causa extraña, bajo cuyo concepto no cabe la culpa del médico, y un régimen de responsabilidad por culpa para los profesionales de la salud.

Teniendo en cuenta que en la actualidad el sistema sanitario funciona sobre la base de una cadena de intervenciones que conducen en últimas a interrogar sobre el lugar de ocurrencia de la infección, la Casación francesa en fallo del 17 junio 2010, ha considerado que en caso de duda sobre el lugar donde se contrae la infección, la víctima no está obligada a demostrar con certeza absoluta el lugar de contaminación, pues le bastará con haber probado el carácter nosocomial de la infección ${ }^{31}$. En este caso, le corresponderá al establecimiento demandado, demostrar que el paciente estaba contaminado antes de la hospitalización.

Igualmente, hay que tener en cuenta que la ley Kouchner, no excluyó del campo de las infecciones indemnizables a las infecciones irresistibles, es decir, a las endógenas, armonizando de este modo las diferencias que se presentaban entre la jurisdicción civil, que no hacía ninguna diferenciación según que las infecciones fueran endógenas o exógenas y la contencioso administrativa, que rechazaba la indemnización de las infecciones endógenas.

En efecto, la Casación francesa consideraba que el carácter endógeno de la infección no excluía su carácter nosocomial, es decir, no era posible asimilar la infección nosocomial irresistible a una causa extraña exoneratoria de responsabilidad, pues la aparición de una infección de naturaleza endógena, no podía considerarse como exterior al hospital en la medida que es durante una intervención, por ejemplo, que se revelaba; pero tampoco la

\footnotetext{
29 ERstein (2011) p. 387.

30 Gibert (2011) p. 421.

31 Cass. 1re civ. 17 juin 2010, n. 09-67.011.
} 
consideraba imprevisible, en la medida que, de acuerdo con su criterio, estas infecciones constituían un riesgo médico bien conocido e inherente a ciertos tipos de intervención; finalmente, tampoco la consideraba irresistible, dado que existen medidas de prevención contra este tipo de infecciones ${ }^{32}$. La posición de la Casación se caracterizó siempre por tomar la solución más ventajosa para la víctima ${ }^{33}$, la que en este caso estaba representada por otorgar una interpretación amplia al concepto 'infecciones nosocomiales' y de este modo, rechazar cualquier distinción entre infecciones endógenas y exógenas.

Por su parte, la jurisprudencia contencioso administrativa era partidaria de limitar la responsabilidad sin culpa solamente a las infecciones exógenas ${ }^{34}$, de este modo, consideraba la naturaleza endógena de la infección como constitutiva de una causa extraña, exoneratoria de responsabilidad ${ }^{35}$, tal como ocurrió, por ejemplo, en un caso fallado el 25 de octubre de 2006 por el Consejo de Estado francés, donde la entidad demandada logró demostrar que la naturaleza anaeróbica del germen que produjo la infección excluía un origen exterior, por lo cual, el juez consideró que la circunstancia de las microlesiones provocadas para la realización de una cirugía de coronarias, al haber facilitado la migración de los gérmenes, no tenía incidencia sobre el carácter endógeno de la infección; es decir, para la jurisdicción, se había producido una asimilación entre el carácter endógeno de la infección y la causa extraña.

Como puede observarse, para el caso de las infecciones hospitalarias en Francia opera, como algunos autores lo denominan, un régimen complejo de indemnización ${ }^{36}$, que combina las reglas de responsabilidad, con las reglas de la solidaridad. De este modo, la consagración de un régimen objetivo de responsabilidad viene respaldado en un esquema donde no solo existe la instauración de un seguro de responsabilidad médica de carácter obligatorio para todos los profesionales de salud y establecimientos de salud ${ }^{37}$, sino también, un sistema de solidaridad nacional. Panorama que no existe en Colombia, donde lejos se está de llegar a implementar un esquema similar en un futuro mediato y que por lo tanto, no puede justificar el paso hacia un régimen objetivo de responsabilidad en esta materia.

Además, se debe tener en cuenta que el recurso a la solidaridad nacional que opera en Francia no ha sido ni siquiera concebido de manera automática, pues para operar se encuentra sometido a ciertas condiciones que definen estrictamente los eventos susceptibles de ser indemnizados por ella. Esta intervención del Estado, que reemplaza el mecanismo habitual del seguro, es entonces de carácter subsidiario y supletorio ${ }^{38}$.

La subsidiariedad reside en la incapacidad de la responsabilidad civil para responder a las necesidades de la indemnización. Es decir, para recurrir a la solidaridad nacional es necesario que la responsabilidad no esté comprometida (condición negativa) ${ }^{39}$, pues si está

32 Gibert (2011) p. 411.

33 BaCACHE (2010); Cass. 1re civ. 4 avr. 2006, n. 05-14094; Cass. 1 re civ. 14 juin 2007, n. 06-10812.

34 BACACHE (2010).

35 Gibert (2011) p. 409.

36 LAmbert-Faivre (2002) p. 362.

37 Ver también Art. L 151-1 Código de Seguros.

38 Arts. L 1142-1, II y L 1142-15 Código Salud Pública.

39 Viney (2002) p. 9; Durry (2002) p. 113. 
implicada, deberá primar sobre la solidaridad permitiendo la indemnización a la víctima. Este carácter subsidiario no debe ser interpretado en un sentido de "accesoriedad" sino de "complementariedad". La intervención de la solidaridad nacional es complementaria en la medida que interviene solamente cuando otro mecanismo de reparación no ha podido tener lugar ${ }^{40}$. Esta intervención complementaria es al mismo tiempo indispensable para satisfacer una necesidad de justicia, en tanto que la aceptación por el paciente de someterse a ciertos riesgos a través de la intervención médica, no puede ser un obstáculo a la reparación del daño causado.

Por otra parte, también se ha establecido que la solidaridad nacional puede tener un carácter supletorio. En tal evento, le es concebido operar en aquellos casos en que a pesar de existir una responsabilidad comprometida, el seguro no ha podido indemnizar a la vícti$\mathrm{ma}^{41}$. En este caso, la solidaridad sustituye al asegurador, configurándose así la expresión de la finalidad que guía esta reforma legislativa, esto es, la aspiración de la reparación del daño.

De otro lado, con el fin de corroborar aún más la falta de claridad con que la jurisprudencia colombiana, con apoyo en el derecho francés, sustenta el paso hacia un sistema de responsabilidad objetiva para el caso de las infecciones intrahospitalarias, es preciso tener en cuenta que Francia recalca la diferencia terminológica existente entre indemnización sin culpa y responsabilidad sin culpa. Reparar un daño significa compensarlo o tratar de que este desaparezca en cabeza de la víctima que lo ha sufrido; responder, en cambio, significa vincular a un responsable, buscar a un culpable, ya que en el sentido clásico del término, solo el autor de una culpa puede verdaderamente responder. Así pues, más que de una responsabilidad sin culpa, debe hablarse de una indemnización sin culpa para este caso concreto.

Es decir, el sistema especial consagrado en Francia frente a los daños por infecciones intrahospitalarias, debe considerarse como una evento de indemnización sin culpa, no de responsabilidad sin culpa, pues como acaba de anotarse lo que opera de entrada es una reparación con apoyo en sistemas de garantía social. Es decir, el seguro obligatorio o el fondo de garantía, según el caso, son quienes tienen a cargo el pago de la indemnización y no la entidad hospitalaria como se pretende en Colombia, debido a la ausencia, se insiste, de un sistema de aseguramiento obligatorio para la responsabilidad médica y de un fondo de garantía para estos eventos.

Se trata, en suma, de un mecanismo de indemnización que combina responsabilidad y solidaridad según una lógica de subsidiariedad, que subordina el recurso a la solidaridad nacional a la ausencia de responsabilidad civil. De este modo, la ley Kouchner otorgó claramente el peso de la indemnización en caso de infecciones nosocomiales sobre el asegurador de la responsabilidad, siendo la solidaridad nacional un modo secundario de indemnización ${ }^{42}$.

Por tradición, la responsabilidad sin culpa del derecho francés, admitida desde el año 1895 , se funda en aquellos casos de ruptura del principio de igualdad frente a las cargas

\footnotetext{
Pontier (1995) p. 76.

41 Chabas (2004) p. 105.

42 Hocquet-Berg (2013) p. 311.
} 
públicas y en los eventos de responsabilidad por riesgo. Hay que recalcar, además, cómo la jurisprudencia francesa ha sido prudente en el reconocimiento de estos eventos de responsabilidad sin culpa, considerando que la responsabilidad del Estado no puede comprometerse de manera general o absoluta. Igualmente, la responsabilidad por riesgo no es de aplicación general en materia administrativa, a pesar de su constante progreso, lo cual obedece primordialmente a razones prácticas de orden financiero.

Así las cosas, observamos cómo el sistema de responsabilidad objetiva para las infecciones nosocomiales del derecho colombiano, no denota una clara correlación con el sistema que según afirma el Consejo de Estado le sirve de fundamento, esto es, con el sistema francés, ya que como se ha indicado, aquí se trata de un régimen de indemnización sin culpa, que obedece a una dinámica ausente en el sistema colombiano, ya que la problemática ha sido enmarcada en lo que se conoce como alea terapéutica, es decir, aquellos daños que se suceden a pesar de no haber culpabilidad en su causación, razón que justifica su indemnización con apoyo en sistemas de garantía social.

\section{B. LOS ERRÓNEOS FUNDAMENTOS DE LA RESPONSABILIDAD EN LA JURISPRUDENCIA COLOMBIANA \\ El Consejo de Estado a través de su fallo del 29 agosto 2013, fundamentó la respon-} sabilidad por daños derivados de una infección nosocomial en la teoría del "riesgo-álea", como una de las modalidades del "riesgo excepcional", cambiando de este modo la tendencia por el reconocimiento de una responsabilidad de corte subjetivo en el campo de la prestación del servicio médico-hospitalario. Según la corporación, esta categoría de riesgo "toma en consideración la probabilidad de que cierto tipo de actividades o procedimientos, pueden dar lugar, quizás con la ineludible mediación del azar o de otro tipo de factores imprevisibles, a la producción de daños sin que medie asomo alguno de culpa" ${ }^{33}$.

La teoría del "riesgo excepcional", de la cual hace uso el Consejo de Estado para fundamentar la responsabilidad médica del ISS en este evento específico de infecciones intrahospitalarias, encuentra sus orígenes en el año $1984^{44}$, cuando la Corporación empezó a utilizarla para fundamentar la responsabilidad en aquellos eventos de imposibilidad de probar la culpa del causante del daño, durante la ejecución de una obra de servicio público y al usarse recursos o medios que colocaban a los particulares o sus bienes en situación de quedar expuestos a un riesgo de naturaleza excepcional, el cual, dada su gravedad, excede las cargas que normalmente deben soportar los particulares como contrapartida de las ventajas que resultan de la existencia de un determinado servicio público.

En este orden de ideas, la tesis del "riesgo excepcional" se emplea en los casos de servicio de energía eléctrica, uso de armas de fuego, aeronaves, vehículos automotores, entre otros, $y$, donde se advierte que el daño no ha sido producido por un mal funcionamiento de la administración ${ }^{45}$. Es decir, la Corporación ha aplicado el régimen de responsabilidad

\footnotetext{
43 Consejo de Estado. Sección Tercera. Agosto 29 de 2013. Exp. 30283.

44 Consejo de Estado. Sección Tercera. Febrero 2 de 1984. Exp. 2744.

45 Yong (2012) p. 351.
} 
FERnÁndez M., Mónica L. " "Las infecciones nosocomiales como un nuevo evento de responsabilidad...”

objetiva por riesgo excepcional en aquellos eventos de daños producidos por cosas o actividades peligrosas ${ }^{46}$.

Olvida la jurisprudencia de hoy que ya el Consejo de Estado había hecho la distinción entre el régimen aplicable en los eventos de daños producidos por la prestación de servicios médicos y aquellos producidos por cosas o actividades peligrosas. En efecto, en el año $1992^{47}$ se había aclarado que en los casos de responsabilidad por la prestación del servicio médico, debía tenerse en cuenta la falla o conducta irregular de la administración, es decir, primaría el sistema subjetivo de responsabilidad.

En efecto, la posición tradicional de la jurisprudencia ha sido la de no considerar la medicina como una actividad riesgosa, pues ello resulta inadmisible ${ }^{48}$, salvo en el caso de empleo de aparatos, instrumentos o elementos que conlleven un riesgo para el paciente y cuyo uso sea comúnmente aceptado y avalado para el diagnóstico y tratamiento de ciertas enfermedades o patologías (v.gr. herramientas de radiología, medios de contrastes, desfibriladores, algunas placas de acero con polo a tierra, etc.), únicos escenarios o eventos en que sería viable aplicar el título de imputación objetivo de riesgo creado o riesgo alea ${ }^{49}$.

Según la jurisprudencia colombiana, la responsabilidad por riesgo alea se ha reconocido en la jurisprudencia francesa en aquellos casos en los cuales "se emplean, por parte de la administración, métodos científicos cuyas consecuencias dañosas aún no son del todo conocidas o cuando, a pesar de ser conocidas, resultan de muy excepcional ocurrencia, en definitiva, cuando se está en presencia del denominado riesgo estadístico" ${ }^{50}$.

Como se puede observar, los fundamentos para la construcción de la denominada teoría del riesgo alea no se corresponden con los supuestos que se involucran en el caso objeto de análisis.

En lo que respecta a Colombia, podríamos afirmar que el marco normativo que regula la materia de infecciones nosocomiales o intrahospitalarias, está constituido de la siguiente manera:

Desde la Ley 09 del 24 enero de 1979, se consideró la salud como un bien de interés público y se establecieron normas de vigilancia y control epidemiológico para el diagnóstico, pronóstico, prevención y control de las enfermedades transmisibles, así como para la divulgación de la información epidemiológica.

Las Resoluciones 04153 de 1993, 0300 de 1998 y el Decreto 2676 de 2000, constituyen el marco normativo sobre el manejo de residuos hospitalarios y similares, y la Resolución n. 4445 de 1996 establece las normas sobre condiciones sanitarias que deben cumplir los establecimientos hospitalarios y similares, todas las instituciones prestadoras de servicio de salud, públicas o privadas o mixtas, en las fases de promoción, prevención, diagnóstico, tratamiento y rehabilitación física o mental.

\footnotetext{
Velásquez (2009) p. 129.

Consejo de Estado. Sección Tercera. Agosto 24 de 1992. Exp. 6754.

8 Consejo de Estado. Sección Tercera. Julio 22 de 2009. Exp. 18069.

49 GIL (2010) p. 522.

50 Consejo de Estado. Sección Tercera. Marzo 26 de 2008. Exp. 16530.
} 
En el año 2006, el Decreto n. 1562 de 1984, fue derogado por el Decreto 3518 del 9 octubre, que creó y reglamentó el Sistema de Vigilancia en Salud Pública (SIVIGILA), con el fin proveer información sobre la dinámica de las situaciones que afectan o pueden afectar la salud de la población, a efecto de orientar las políticas y la planificación en salud pública, tomar las decisiones para la prevención y control de enfermedades y factores de riesgo en salud. Conforme a este Decreto, los departamentos, distritos y municipios, deben crear Comités de Vigilancia en salud pública en sus respectivas jurisdicciones, los cuales serán presididos por el Director Territorial de Salud. En su artículo 37, se establece que los siguientes comités actuarán como Comités de Vigilancia en Salud Pública: Comités de Vigilancia Epidemiológica (COVE), Comités de Infecciones Intrahospitalarias, Comités de Estadísticas Vitales, Comités de Vigilancia Epidemiológica Comunitaria (COVECOM) y otros comités afines.

Por su parte, la Constitución de 1991, consagró que la seguridad social es un servicio público de carácter obligatorio, prestado bajo la dirección, coordinación y control del Estado y aplica los principios de descentralización, universalidad, solidaridad, equidad, eficiencia y calidad al servicio de salud en Colombia. Con esta consagración se modificó el Sistema Nacional de Salud, vigente desde 1975.

Bajo esta perspectiva, la Ley 100 de 1993, creó el nuevo Sistema General de Seguridad Social en Salud y dentro de este, estableció la "Acreditación en Salud" como mecanismo voluntario para mejorar la Calidad de los Servicios de Salud ${ }^{51}$.

El Decreto 2174 de 1996, derogado posteriormente por el Decreto 2309 de 2002, reglamentó por primera vez el Sistema Obligatorio de Garantía de Calidad para las EPS e IPS y definió la acreditación como un procedimiento sistemático, voluntario y periódico, orientado a demostrar el cumplimiento de estándares de calidad superiores a los requisitos mínimos de prestación de servicios de salud. Actualmente, el Decreto 1011 del 3 abril de 2006, define la "Calidad de la Atención en Salud" como "la provisión de servicios de salud a los usuarios individuales y colectivos de manera accesible y equitativa, a través de un nivel profesional óptimo, teniendo en cuenta el balance entre beneficios, riesgos y costos, con el propósito de lograr la adhesión y satisfacción de dichos usuarios” ${ }^{72}$. De acuerdo con el artículo 4 del citado Decreto 2174 de 1996, el SOGCS está compuesto por el Sistema Único de Habilitación, la Auditoría para el Mejoramiento de la Calidad de la Atención de Salud, el Sistema Único de Acreditación y el Sistema de Información para la Calidad.

Se hace alusión a este aspecto, pues se considera como fundamental para la comprensión de la materia objeto de reflexión, dado que el cumplimiento de la normatividad que sustenta el Sistema Nacional de Salud, el registro, control, prevención e investigación de las infecciones intrahospitalarias hace parte, en últimas, de los requisitos esenciales que debe cumplir cualquier IPS, ARS o $\mathrm{ESE}^{53}$ para la certificación por parte de las autoridades

\footnotetext{
51 Art. 186.

52 Decreto Nº 1011 (3/4/2006), Art. 1, Por el cual se establece el Sistema Obligatorio de Garantía en Calidad de la Atención de Salud del Sistema General de Seguridad Social en Salud (SOGCS).

53 Administradora del Régimen Subsidiado (ARS) o Empresa Social del Estado (ESE).
} 
de salud. En efecto, el hecho de considerarse la salud como un derecho fundamental ${ }^{54}$, cuya prestación se desarrolla como un servicio público esencial, impone el deber al Estado, a través de sus organismos delegados, de asumir la verificación de todos los requisitos que el ordenamiento considera necesarios para asegurar unos estándares mínimos de calidad en la prestación del servicio de salud.

El art. 14 de la Ley 1122 de enero 9 de 2007, señala las pautas para estructurar el aseguramiento, es decir, los requisitos que las entidades del sector deben cumplir para que la administración pueda asegurar el acceso a las prestaciones derivadas del servicio público de salud, como servicio esencial, entre las cuales está la administración del riesgo financiero, la gestión del riesgo de salud, la articulación de los servicios que garanticen el acceso efectivo, la garantía de la calidad en la prestación de los servicios y la representación del afiliado ante el prestador. Todos estos requisitos deberá tenerlos en cuenta la Administración pública en el momento de autorizar y habilitar a EPS $(S)^{55}, \mathrm{PSS}^{56}, \mathrm{ARL}^{57}$ y empresas de medicina prepagada, interesadas en gestionar el ramo.

En este orden de ideas, cuando la autoridad competente analiza una solicitud, debe revisar si las calidades acreditadas aseguran que no se vaya a presentar una falla del servicio, pues los mecanismos de "autorización" y "habilitación" se dirigen a evitar que se presenten omisiones, retardos injustificados, en general, irregularidades o ineficiencias en la prestación del servicio ${ }^{58}$. Así pues, una real y efectiva verificación de todos los requisitos y condiciones exigidas para una prestación eficiente del servicio de salud, resulta ser una medida de gran importancia, no solo para garantizar la calidad de las prestaciones ofrecidas, sino también, para controlar y prevenir, en este caso concreto, las infecciones intrahospitalarias y en consecuencia, evitar los posibles daños o lesiones que puedan derivar de las mismas.

Igualmente, hay que tener en cuenta que la Ley 1438 de 2011, estableció la creación del "Instituto de Evaluación Tecnológica"59, el cual es responsable de la evaluación de tecnologías en salud basada en la evidencia científica, guías y protocolos sobre procedimientos, medicamentos y tratamiento, de acuerdo con los contenidos del Plan de Beneficios. Desde esta perspectiva, podríamos concluir que se trata de un organismo que tiene también injerencia en las políticas de control y vigilancia de infecciones nosocomiales, ya que según la norma, entre sus funciones está la de diseñar estándares, protocolos y guías de atención en salud, basados en evidencia científica, que sirvan de referente para la prestación de los servicios de salud.

Finalmente, es de anotar que en el año 2006, se expidió la Resolución 1446 de mayo 8, en cuyo Anexo Técnico se establecieron los lineamientos para la vigilancia de eventos adversos, siendo en junio de 2008 publicados los "Lineamientos para la implementación

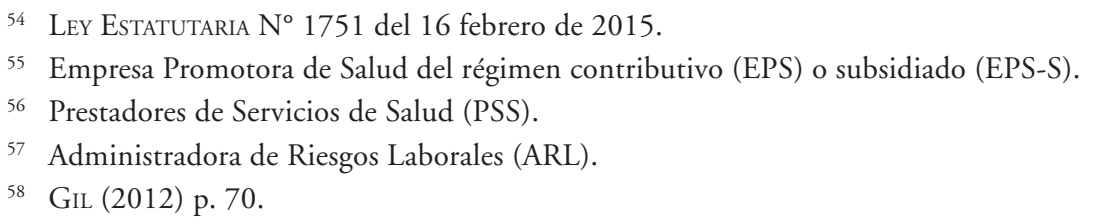


de la política de seguridad del paciente", donde se incluye la prevención de las infecciones asociadas al cuidado de la salud.

En lo atinente a los denominados eventos adversos, el citado Anexo Técnico los define de la siguiente manera: "Lesiones o complicaciones involuntarias que ocurren durante la atención en salud, los cuales son más atribuibles a esta que a la enfermedad subyacente y que pueden conducir a la muerte, la incapacidad o al deterioro en el estado de salud del paciente, a la demora del alta, a la prolongación del tiempo de estancia hospitalizado y al incremento de los costos de no calidad. Por extensión, también aplicamos este concepto a situaciones relacionadas con procesos no asistenciales que potencialmente pueden incidir en la ocurrencia de las situaciones arriba mencionadas" ${ }^{60}$.

Por su parte, los estudios de prevalencia de eventos adversos en Latinoamérica señalan a la infección intrahospitalaria como el "evento adverso" más frecuente y como tal, el primer reto declarado por la Alianza Mundial para la Seguridad de los Pacientes ${ }^{61}$.

En Francia, igualmente, desde la promulgación del Decreto n. 1408 del 12 noviembre de 2010, se precisa que las infecciones nosocomiales constituyen un evento adverso (événement indésirable), el cual es definido como todo incidente perjudicial a un paciente hospitalizado, ocurrido durante la realización de un acto de prevención, investigación o de un tratamiento (art. R-6111-1) ${ }^{62}$.

Pero, no obstante estos criterios, la jurisprudencia colombiana en la decisión que aquí se analiza, indica que los daños derivados de este tipo de infecciones no pueden ser considerados como "eventos adversos", asociados al incumplimiento de la obligación de seguridad y vigilancia jurídicamente exigible a las instituciones prestadoras de servicios de salud, sino que deben ser analizados desde un régimen objetivo de responsabilidad. Es decir, la jurisprudencia colombiana, en contravía incluso con los postulados internacionales, se niega a reconocer que las infecciones nosocomiales son un evento adverso, lo cual genera una consecuencia directa frente el régimen de responsabilidad a aplicar.

En efecto, en el afán de excluir los daños derivados de las infecciones intrahospitalarias de la categoría eventos adversos, insistiendo en que hacen parte de un sistema objetivo de responsabilidad, no solo se atenta contra el citado principio de primacía del sistema subjetivo aplicable a los daños producidos por la prestación de servicios médicos, sino además, se desconoce la clara distinción que existe en materia de responsabilidad médica, atendiendo a la diferencia de fundamento o criterio obligacional, esto es, la distinción que existe entre la responsabilidad que deriva del desconocimiento de la lex artis y aquella derivada del incumplimiento de la obligación de seguridad. Obligación de seguridad entendida como el "conjunto de elementos estructurales, procesos, instrumentos y metodologías basadas en

60 Resolución No 1446 (8/5/2006), Por la cual se define el sistema de información para la calidad y se adoptan los indicadores de monitoría del Sistema Obligatorio de Garantía de Calidad de la atención en salud.

61 Ministerio de la Protección Social (2010). República de Colombia. Guía Técnica Buenas Prácticas para la Seguridad del Paciente en la Atención en Salud. Detectar, prevenir y reducir el riesgo de infecciones asociadas con la atención en salud.

62 Clément y Clément (2011) p. 139. 
evidencias científicamente probadas que propenden por minimizar el riesgo de sufrir un evento adverso en el proceso de salud o mitigar sus consecuencias" ${ }^{33}$.

Por lo tanto, resulta erróneo fundamentar en un criterio objetivo de imputación todos los casos de daños derivados de infecciones nosocomiales, pues en este ámbito pueden existir casos donde existe una conducta culposa de por medio y otros en los que el daño se produce sin que medie asomo de culpa. Por lo tanto, sería más justo hablar de una obligación de seguridad incumplida, que no permita salir del ámbito subjetivo de la responsabilidad, sino más bien, permitir que la entidad demandada desvirtúe una presunción de culpa o falla, que podría operar considerando que dicha obligación es de resultado.

\section{LA FALTA DE CONDICIONES NO PERMITE AVANZAR HACIA UN SISTEMA OBJETIVO DE RESPONSABILIDAD EN COLOMBIA}

\section{A. Esbozo de los principales argumentos en CONTRa de este nUeVo EVEnto de} RESPONSABILIDAD

La decisión promulgada, ha desatado en el medio colombiano un sinnúmero de reacciones, no solo del sector de la salud, sino también, de connotados juristas nacionales. Entre los principales aspectos que se esbozan en contra del fallo está el hecho de ser una decisión antijurídica, injusta e inconveniente, debido a que "atenta contra la dinámica de los principios constitucionales (i), contra el análisis económico del derecho (ii) y contra la teleología del denominado riesgo excepcional" ${ }^{64}$.

Encuadrar las infecciones nosocomiales dentro del marco de la responsabilidad objetiva, genera un impacto importante en el contexto colombiano, no solo en el campo de la salud, sino también, en la economía y en la sociedad en general, si se piensa tan solo, por ejemplo, en los sobrecostos que implica su tratamiento ligados a la prolongación de la estancia hospitalaria, a los altos costos de los antibióticos, las reintervenciones quirúrgicas, igualmente, los costos sociales, representados en las pérdidas de salarios, de producción, el impacto en la familia, la comunidad, el compromiso de los indicadores de calidad y buen nombre de las instituciones, las complicaciones ético legales implicadas en el proceso y los índices de mortalidad de la población, entre otros.

Dichos impactos negativos han sido reconocidos a nivel mundial, pues el tema de las infecciones intrahospitalarias no es un problema local sino internacional. En efecto, la Organización Panamericana de la Salud (OPS), organizó desde el año 1989, es decir, desde hace 25 años, una Conferencia Regional sobre Prevención y Control de Infecciones Nosocomiales, en la cual participó Colombia, entre otros países de la región; y, al igual que la OMS, estos organismos, han elaborado un sinnúmero de documentos que hacen alusión a este grave problema de Salud Pública en el mundo, pues las "Infecciones Asociadas a la Atención de la Salud (IAAS)", entre las que se incluyen las nosocomiales, se consideran como un problema de salud pública importante debido a la frecuencia con que se produ-

\footnotetext{
63 Decreto No 1011 del 3 abril de 2006, art. 3, núm. 3.

64 TAMAYo (2014) p. 21.
} 
cen, la morbilidad y mortalidad que provocan y la carga que imponen a los pacientes, al personal sanitario y a los sistemas de salud ${ }^{65}$.

En el año 2002 se realizó la Asamblea Mundial de la Salud, en la cual se reconoció la "seguridad del paciente" como un problema serio de salud pública, especialmente en los países en desarrollo como Colombia, donde el riesgo de infecciones intrahospitalarias es mayor. Como una respuesta a dicho problema la OMS creó en el año 2004 la Alianza Mundial para la Seguridad del Paciente, encargada básicamente de propiciar la colaboración internacional y la acción de los Estados miembros a fin de difundir y acelerar las mejoras en materia de seguridad del paciente.

De acuerdo con el informe presentado en el año 2010 por la Asociación Colombiana de Infectología: "En el 2009, el Ministerio de la Protección Social, mediante la conformación de una red en resistencia antimicrobiana e infección intrahospitalaria; presentó un informe de diagnóstico de la situación actual de la infección intrahospitalaria en Colombia. En dicho informe se resalta que a pesar de la normatividad vigente concerniente a estándares de calidad y habilitación de atención de salud, aún existe en el país un subregistro importante, lo que no permite conocer adecuadamente la magnitud del problema. El dato global oficial registrado es de sólo 1.6\%, mientras que diferentes estudios realizados en algunas instituciones permiten colegir que las cifras en Colombia son mucho más altas, resaltando el impacto de las infecciones asociadas al uso de dispositivos vasculares, respiratorios, urinarios y asociadas a procedimientos quirúrgicos. Así mismo, este tipo de infecciones son las que se han descrito en la literatura como las principales causas de mortalidad y generadoras de costos extra para su atención" ${ }^{66}$.

El citado informe igualmente señala que debido no solo al impacto económico, sino también, en vidas humanas, se ha generado que la prevención de las infecciones asociadas al cuidado de la atención en salud, se haya convertido en uno de los cuatro objetivos del Medicare y Medicaid en los Estados Unidos, para el mejoramiento de la calidad hospitalaria. Igualmente, en una de las ocho metas para la seguridad del paciente por la Joint Comission y una de las cuatro prioridades para investigación del citado programa de "Seguridad del Paciente" de la OMS.

En América Latina, con participación de hospitales de Colombia, Argentina, Costa Rica, México y Perú, se realizó el que ha sido considerado el primer estudio llevado a cabo en la región para medir los eventos adversos que ocurren como resultado de la atención médica en los hospitales, denominado "Estudio de Eventos Adversos (IBEAS)", dirigido por el gobierno español, la OMS y la OPS, donde se encontró que el 37.14\% de los eventos adversos reportados estaban relacionados con infecciones nosocomiales, convirtiéndose de este modo, en el conjunto de eventos adversos más prevalente identificado en el estudio, por lo cual, se llamó la atención en la necesidad de establecer estrategias dirigidas a la minimización de estas infecciones ${ }^{67}$.

65 Organización panamericana de la Salud -OPS- (2012), p. 7.

66 Asociación Colombiana de Infectología Capitulo Central (2010) p. 5.

67 Ministerio de Sanidad, Política Social e Igualdad de España (2010) p. 111. 
Los estudios hechos por el Ministerio de Protección Social en Colombia ${ }^{68}$, estiman que en los países desarrollados, entre el 5\% y el $10 \%$ de los pacientes contrae una o más infecciones, y se considera que entre el $15 \%$ y el $40 \%$ de los pacientes internados en atención crítica resulta afectado. Por su parte, en los entornos de bajos recursos, se estima que las tasas de infección pueden superar el 20\%, pero los datos disponibles son escasos, por lo cual, el Ministerio resalta que se necesita más investigación en forma urgente, para poder evaluar el peso de la enfermedad en los países en vías de desarrollo. El Ministerio informa, igualmente, que en los países desarrollados, las infecciones asociadas con la atención en salud, son responsables de más de 20.000 muertes por año y de estas un $4.5 \%$ corresponden a pacientes quirúrgicos.

Así pues, dentro de este contexto si se quiere desalentador, el Consejo de Estado colombiano pretende implementar un régimen de responsabilidad objetiva para los daños derivados de infecciones nosocomiales que, primero, no corresponde a una construcción teórica adecuada y, segundo, no estará garantizado por ningún aseguramiento obligatorio, ni mucho menos contará con un apoyo por parte de la solidaridad nacional a título de fondo de garantía, tal como ocurre en Francia.

Recordemos que históricamente la evolución hacia los sistemas de responsabilidad objetiva, ha sido posible gracias al papel que ha representado el seguro de responsabilidad civil, el cual se ha erigido en canon normativo en determinados ámbitos en las sociedades desarrolladas, porque en ellas se dispone de los mecanismos necesarios para la distribución y socialización de los daños (v.gr. Seguros de responsabilidad civil, fondos de garantía, etc.); recordemos, además, cómo la migración hacia dichos sistemas se hizo de manera gradual, con un sentido limitativo, es decir, solamente para aquellas actividades que implicaban un riesgo considerablemente anormal en relación con los estándares medios y donde el criterio de la culpa resultaba insuficiente para alcanzar determinados objetivos sociales ${ }^{69}$.

Es de tener en cuenta que en Francia este sistema de responsabilidad de corte objetivo y el diseño de un sistema de indemnización con respaldo en la solidaridad nacional, vía la constitución de un fondo de garantía, responde a una política de gobierno, donde claramente se evidencia que el paso hacia una responsabilidad "objetiva" fue respaldada en la constitución de un seguro de responsabilidad civil obligatorio.

En Colombia, al contrario, falta un marco normativo que sustente el paso hacia una responsabilidad objetiva, no existen proyectos legislativos dirigidos a la consagración de un seguro de responsabilidad civil médica con carácter obligatorio y mucho menos a la constitución de fondos de garantía para los eventos de alea nosocomial ${ }^{70}$. Un sistema de tal envergadura, supondría un profundo estudio previo desde la sociología de derecho, que indique los efectos que ello produciría en la vida social colombiana en general y en el Sistema de Seguridad Social en Salud en particular. Por lo tanto, la jurisprudencia no puede dar este paso a través de la consagración sin más de un régimen objetivo de responsabilidad, una solución que no consulta sobre los fines políticos que pretende el Estado colombiano.

\footnotetext{
68 Ministerio de la Protección Social, República de Colombia (2010) p. 21.

69 Reglero (2008) Tomo I, p. 268.

70 FERnÁNdEZ (2008) p. 545.
} 


\section{B. Mecanismos alternativos de SOlución Para El EVENTO de DaÑos DERIVAdos de} INFECCIONES INTRAHOSPITALARIAS

No obstante las continuas amenazas de fallas en los sistemas de salud, se considera que es necesario enfrentar los problemas que se puedan presentar en la prestación de los servicios de salud, de una manera adecuada, pues la solución no está en declarar la responsabilidad sin más, sin indagar sobre la culpabilidad, la negligencia, etc. en la que hubieren podido incurrir los sujetos investigados, pues soluciones como la reciente de la jurisprudencia colombiana, no hacen más que resquebrajar el sistema sanitario, desde un punto de vista económico y de políticas en el sector, lo que en últimas podría impactar en la sostenibilidad del Sistema Nacional de Salud.

Una simple lectura de la mencionada sentencia, deja entrever que el Consejo de Estado no fue activo en la solución del conflicto, no verificó, por ejemplo, si una infección idéntica se había presentado en otros casos en la misma época en la Institución demandada, no verificó si se cometieron errores en los procesos de asepsia, no indagó sobre el cumplimiento de los protocolos de seguridad para el tratamiento y control de las infecciones nosocomiales, entre otros; sino que decidió tomar el camino más simple: imputar la responsabilidad y a título de responsabilidad objetiva.

Si bien es cierto que un problema de salud pública no se podría resolver, presentando como único argumento el impacto que genera en las finanzas, al atentar contra la estabilidad económica del sistema, debido a que están de por medio derechos constitucionales involucrados, no debe perderse de vista que el problema objeto de análisis gira en torno a aquellos eventos donde se presenta un daño en ausencia de culpabilidad por parte del agente causante, es decir, estamos en presencia, como antes se indicó, de aquellos eventos de "alea terapéutica", que no pueden ser indemnizados a la luz de la responsabilidad como lo pretende la justicia colombiana. En efecto, la decisión rompe con la adecuada lógica indemnizatoria, pues la justicia compensatoria requiere de la eliminación de pérdidas no merecidas o injustificables causadas por la falta del causante ${ }^{71}$. De tal modo que, en este caso, la compensación de la víctima debe quedar protegida a través de un sistema de contrato de seguro o de fondos de garantía, tal como opera actualmente en el sistema francés.

Así pues, en ausencia de un marco normativo que sustente el paso a una responsabilidad objetiva en este ámbito, sobre todo, como se ha dicho, una garantía del tipo aseguramiento obligatorio de la responsabilidad y la existencia de un fondo de garantía que asuma este tipo de indemnizaciones, una solución alternativa acorde con el contexto colombiano, podría estar quizás, como arriba se indicó, en la consagración de un sistema de responsabilidad por falla (culpa) presunta con fundamento en una obligación de seguridad de resultado, y además, en una verdadera integración de las políticas de salud con estrategias de desarrollo en este sector y la reducción de daños a través de mecanismos adecuados que promuevan la prevención y el control de las infecciones intrahospitalarias.

En efecto, no parece justo atribuir automáticamente una responsabilidad en eventos de daños derivados de infecciones nosocomiales. Parecería adecuado indagar primero si hubo alguna conducta negligente o culposa, incluso por vía de presunción, con el fin de fa-

71 Coléman (2013) p. 58 
FERnÁNDEZ M., Mónica L. " "Las infecciones nosocomiales como un nuevo evento de responsabilidad...”

vorecer la posición de la víctima frente a la dificultad probatoria que este tipo de eventos le genera. Esta indagación sobre la culpabilidad se justifica, además, porque los estudios señalan que este tipo de infecciones son en parte evitables y su frecuencia puede ser disminuida sensiblemente.

Si bien se acepta que hacer asumir el riesgo a la parte fuerte de la relación obligacional, es económicamente admisible y filosóficamente aceptable ${ }^{72}$, en este caso específico de daños derivados de infecciones nocosomiales donde no se compromete una falta o conducta culposa, no sería justo lograr ese resultado por la vía de la responsabilidad objetiva.

En cuanto a la prevención de las infecciones intrahospitalarias, desde los propios estudios del Proyecto SENIC (Study on the Efficacy of Nosocomial Infection Control), se logró concluir que la vigilancia de la infección nosocomial y las actividades de prevención y control, se asocian a un descenso de las tasas de infección hospitalaria, por lo que constituye un método eficaz para la prevención de las infecciones nosocomiales. De acuerdo con dichos estudios, una tercera parte de las infecciones nosocomiales se pueden prevenir al instaurar su vigilancia, por consiguiente, un programa de prevención y control eficaz de estas infecciones, puede reducir sustancialmente los costos de la atención sanitaria y, lo que es más importante, la morbilidad y mortalidad asociada a ellas ${ }^{73}$.

Se insiste entonces en la necesidad de una política de prevención de las infecciones nosocomiales, que si bien implica una inversión humana y financiera ${ }^{74}$, resulta indispensable en aras de la buena calidad en la prestación del servicio y en razón a que el medio ambiente hospitalario es una fuente importante de gérmenes, cuya causa si bien resulta a veces difícil de determinar, la ciencia ha demostrado que el caso de transmisión alterna de germenes patógenos de un enfermo a otro, es accesible a las medidas preventivas ${ }^{75}$.

Juegan aquí un papel fundamental las modernas técnicas de gestión del riesgo o risk management sanitario, cuyo objetivo esencial es poner a cargo de quien produce el riesgo, el deber de prevenirlo, por medio de esta alternativa entendida como el "conjunto de actividades destinadas a minimizar el riesgo de que se produzca un efecto adverso durante la asistencia, o a disminuir sus consecuencias negativas; constituye un conjunto de medidas de autoprotección, que buscan prevenir o evitar las amenazas reales o potenciales de pérdidas económicas debidas a accidentes, lesiones o negligencia médica”76.

Este mecanismo de gestión y control del riesgo clínico que empezó a ejecutarse en USA hacia mediados de los años setenta para tratar de reducir los daños causados por la asistencia médica y frenar los gastos de los procesos y de los resarcimientos a ellos conexos, se basa en un seguimiento sistemático de los riesgos médicos a través de una unidad de risk management existente en cada estructura organizativa ${ }^{77}$. Su propósito no es buscar culpables, ni garantizar la ausencia de siniestros, sino el de agotar las posibilidades, dentro de

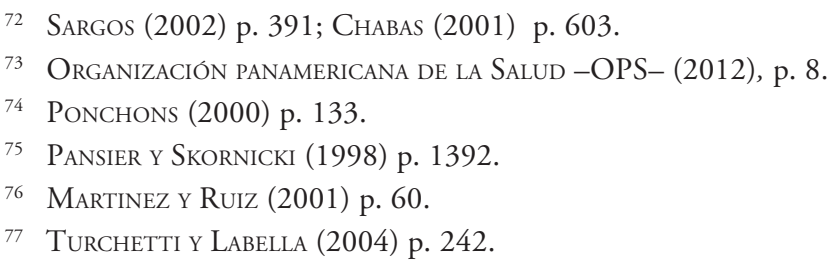


unos costes sostenibles, de anticipación de consecuencias no deseables en sucesivas repeticiones del acto o en el futuro de los resultados derivados de esos actos ${ }^{78}$.

Aunque si bien este sistema con las mismas dimensiones de USA no se ha logrado en Sudamérica, un adecuado sistema de control del riesgo resulta necesario debido a la extensión de los daños derivados de infecciones intrahospitalarias. En Colombia, por ejemplo, podríamos decir que existe un déficit general de reflexión institucional al respecto y la ausencia de una metodología global uniforme para la gestión de los riesgos. Existe incluso evidencia de Instituciones de Salud que no cuentan aun ni siquiera con programas de prevención y control de infecciones asociadas a la atención en salud, igualmente, se considera que el conocimiento de la problemática es sectorizado y ligado a grupos de trabajo ubicados en las regiones más pobladas del país ${ }^{79}$.

Por otra parte, se requeriría de una mayor eficiencia en los sistemas de autorización y habilitación de las entidades por parte de la administración y en el cumplimiento efectivo del Sistema Obligatorio de Calidad en Salud, pues las infecciones intrahospitalarias o nosocomiales son un indicador que mide la calidad de los servicios prestados. Actualmente, la eficiencia de un hospital no solo se mide por los índices de mortalidad, sino también, se toma en cuenta el índice de infecciones hospitalarias. En tal sentido, no se puede considerar eficiente un hospital que tiene una alta incidencia de infecciones adquiridas durante la estadía de los pacientes en él.

Compartimos, además, la opinión de quien considera que la negligencia en las labores de verificación, puede ocasionar que un daño médico sea imputable incluso al Estado, por omitir su deber de garante del derecho fundamental a la salud, a través de sus competencias de intervención y regulación ${ }^{80}$.

Finalmente, hay que tener en cuenta que estos mecanismos no solo tienen que ver con la gestión hospitalaria y con la vigilancia y el control administrativos, sino además, con aquellos relacionados con la eficacia de la ciencia, que permitan en últimas contribuir al bienestar en la salud de todas las personas, es decir, la solución al problema va vinculado, además, a la necesaria intervención del Estado a través de políticas de apoyo a las investigaciones en ciencia y tecnología que estén dirigidas hacia estos objetivos, de forma tal que se logre la eficacia técnica requerida para afrontar de modo más eficiente este tipo de infecciones en el medio ambiente hospitalario.

Empero, mientras se logra la ejecución de las medidas alternativas antes sugeridas, Colombia y más concretamente sus entidades hospitalarias, tendrán que seguir respondiendo por estos eventos, acatando la decisión de la jurisprudencia, según la cual: “.... el Consejo de Estado, si bien no se ha ocupado de desarrollar una dogmática específica aplicable a los casos de daños derivados de infecciones nosocomiales en los que no existe falla probada del servicio, sí ha trazado unas primeras pautas para afirmar, en consonancia con la tendencia que impera en el derecho comparado, que estos deben ser analizados desde un régimen objetivo de responsabilidad, que en nuestro caso sería el de riesgo excepcional”.

78 Martínez y Ruiz (2001) p. 53.

79 Villalobos et al. (2014) p. 76.

80 GiL (2012) p. 81 


\section{BIBLIOGRAFÍA CITADA}

Asociación Colombiana de Infectología Capítulo Central (2010): Guías de Práctica Clínica para la Prevención de Infecciones Intrahospitalarias Asociadas al Uso de Dispositivos Médicos.

BACACHE, Mireille (2010): "La responsabilité médicale sans faute: passé, présent et avenir" en AA.VV., Liber Amicorum Christian Larroumet (Paris: Económica) s.p.

Castelletta, Angelo (2002): Responsabilité médicale. Droits des malades (Paris, Dalloz).

Chabas, Françoise (2001): "La réparation des conséquences de l'aléa thérapeutique", Juris-Classeur Périodique, II, 10493: pp. 603-607.

Chabas, Françoise (2004): Cien años de responsabilidad civil en Francia (trad. Mauricio Tapia, Paris, Van Dieren).

Clément, Jean - Marie y Clément, Cyril (2011): Mémento de droit hospitalier (Paris, Berger-Levrault).

Coléman, Jules (2013): “La moralidad de la responsabilidad extracontractual objetiva”, en Hernández, Carlos y Ortega, Santiago (edit.), Los costos de los costos de los accidentes (Bogotá, Universidad Libre) pp. 48-92.

Dorsner-Dolivet, Annick (2006): La responsabilité du médecin (Paris, Económica).

Durry, George (2002) : "Responsabilité médicale et solidarité nationale", Risques, No. 49 : pp. 113-118.

ERstein, Lucienne (2011): "Indemnisation des infections nosocomiales", La Semaine Juridique, No. 14, 387.

FERnÁNDEZ, Mónica (2008a): "El alea terapéutica como límite a las obligaciones médico-hospitalarias. Una perspectiva desde el derecho comparado", Prolegómenos. Derechos y Valores, Vol. XI, No. 22: pp. 15-28.

Fernández, Mónica (2008): La responsabilidad médica. Problemas actuales (Bogotá, Grupo Editorial Ibáñez).

GIBERT, Sabine (2011): Guide de responsabilité médicale et hospitalière. Quelle indemnisation du risque médical aujourd'hui? (Paris, Berger-Levrault).

GIL, Enrique (2010): Responsabilidad extracontractual del Estado (Bogotá, Ibáñez, cuarta edición).

GIL, Enrique (2012): La responsabilidad médica derivada de los actos administrativos en el sector salud (Bogotá, Universidad Externado de Colombia).

Hocquet-Berg, Sophie (2012): "Responsabilité médicale sans faute. Infection nosocomiale", JurisClasseur, Fasc. 440-55: pp. 1-27.

Hocquet-Berg, Sophie (2013): "Infections nosocomiales: débiteur de la réparation. Commentaire a Cass. 1 re civ., 19 juin 2013, N 12-20.433”, Responsabilité civile et assurances, No. 10, comm. 311.

Lambert-Faivre, Yvonne (2002): "La responsabilité médicale: la loi du 30 décembre modifiant la loi du 4 mars 2002", Dalloz, No. 6: pp. 361-365.

Lambert-Faivre, Yvonne (2004): Droit du dommage corporel. Systèmes d'indemnisation (Paris, Dalloz). 
LANGLOIS, Jean (2000): Les infections nosocomiales et les infections à l'occasion des soins hors de l'Hôpital. Rapport adopté lors de la session du Conseil nationale de l'Ordre des médecins du 30 juin 2000. Disponible en https:/www.conseil-national.medecin.fr/infectionsnosocomiales

Legros, Bérengère (2004) : "État des lieux sur les différents régimes d'indemnisation des conséquences des accidentes médicaux”, Médecine \& Droit : pp. 1-21.

Martinez, Francisco y Ruiz, José (2001): Manual de gestión de riesgos sanitarios (Madrid, Ediciones Díaz de Santos).

Ministerio de la Protección Social, República de Colombia (2010): Guía Técnica Buenas Prácticas para la Seguridad del Paciente en la Atención en Salud. Detectar, prevenir y reducir el riesgo de infecciones asociadas con la atención en salud.

Ministerio de Sanidad, Política Social e Igualdad de España (2010): Estudio ibeas. Prevalencia de efectos adversos en hospitales de Latinoamérica.

NodArse, Rafael (2002): "Visión actualizada de las infecciones intrahospitalarias", Revista Cubana de Medicina Militar, Vol. 31, No. 3: pp. 201-208.

Organización Mundial de la Salud -OMS- (2003): Prevención de las infecciones nosocomiales. Guía práctica. (OMS, 2a. Edición).

Organización PANAMERICANa de la SALUd -OPS- (2012): Vigilancia Epidemiológica de las Infecciones Asociadas a la Atención de la Salud - IAAS -.

PAnsier, Frédéric-Jérôme y SKornicki, F (1998): "La faute et l'accident en matière de responsabilité médicale", Gazette du Palais, pp. 1391-1394.

Ponchons, François (2000): La securité des patients à l'hôpital (Paris, Berger-Levrault).

Pontier, Jean-Marie (1995): "La prise en charge collective de l'aléa thérapeutique. L'État et les fonds de garantie” en Truchet, Didier (edit.), L'indemnisation de l'aléa thérapeutique (Paris, Dalloz) pp. 73-85.

Reglero, Fernando (2008): "Los sistemas de responsabilidad civil”, en Reglero, Fernando (edit.), Tratado de Responsabilidad Civil. Tomo I (Pamplona, Aranzadi) pp. 247-300.

SARGoS, Pierre (2002): "Évolution et mise en perspective de la jurisprudence de la Cour de cassation en matière de responsabilité civile des médecins", en AA.VV., Droit et économie de l'assurance et de la santé. Mélanges en l'honneur de Yvonne Lambert-Faivre et Denis-Clair Lambert (Paris, s.e.) pp. 375-394.

TAMAYO, Javier (2014): "Responsabilidad por infecciones intrahospitalarias", Ámbito Jurídico, No. 38: p. 21.

Turchetti, Giuseppe y Labella, Barbara (2004): "La gestione del rischio" en Comandé, Giovanni y TurchetTI, Giuseppe (edit.), La responsabilità sanitaria. Valutazione del rischio e assicurazione (Padova, Cedam) pp. 223-308.

VELÁsQueZ, Obdulio (2009): Responsabilidad civil extracontractual (Bogotá, Universidad de la Sabana - Temis).

Villalobos, Andrea et al. (2014): "Vigilancia de infecciones asociadas a la atención en salud, resistencia bacteriana y consumo de antibióticos en hospitales de alta complejidad, Colombia, 2011”, Biomédica, No. 34: pp. 67-80. Disponible en: http://dx.doi. org/10.7705/biomedica.v34i0.1698 
FernÁndez M., Mónica L. — "Las infecciones nosocomiales como un nuevo evento de responsabilidad..."

VINEY, Geneviève (2002): "L'indemnisation des risques sanitaires résultant du fonctionnement du système de santé", Droit des affaires, No. 53 : pp. 9-21.

WeLsh, Sylvie (2003): Responsabilité du médecin (Paris, Litec).

YONG, Samuel (2012): Introducción a la responsabilidad pública y privada (Bogotá, Universidad Santo Tomás, segunda edición).

\section{JURISPRUDENCIA CITADA}

Colombia:

Consejo de Estado. Sección Tercera. Agosto 29 de 2013. Exp. 30283.

Consejo de Estado. Sección Tercera. Junio 11 de 2014. Exp. 27089.

Consejo de Estado. Sección Tercera. Septiembre 10 de 2014. Exp. 27771.

Consejo de Estado. Sección Tercera. Marzo 26 de 2008. Exp. 16530.

Consejo de Estado. Sección Tercera. Marzo 24 de 2001. Exp. 20836.

Consejo de Estado. Sección Tercera. Agosto 19 de 2009. Exp. 17733.

Consejo de Estado. Sección Tercera. Febrero 2 de 1984. Exp. 2744.

Consejo de Estado. Sección Tercera. Agosto 24 de 1992. Exp. 6754.

Consejo de Estado. Sección Tercera. Julio 22 de 2009. Exp. 18069.

Consejo de Estado. Sección Tercera. Marzo 26 de 2008. Exp. 16530.

Francia:

Cass. 1re civ. 9 déc. 1986, n. 84-15753.

Cass. 1re civ., 29 juin 1999, n. 97-15.818, n. 97-21.903 y n. 97-14.254.

Cass. 1 re civ. 14 juin 2007. n. 06-10812.

Cass. 1 re civ. 17 juin 2010, n. 09-67.011.

Cass. 1 re civ. 4 avr. 2006, n. 05-14094.

Conseil d'État, 25 oct. 2006, n. 275700.

Conseil d'État, 9 déc. 1988 , n. 65087.

\section{NORMAS CITADAS}

Colombia

Ley $N^{\circ} 09$ (24/1/1979), Por la cual se dictan medidas sanitarias.

Resolución n. 0300 (1/4/1998), Por la cual se fijan mecanismos para el manejo de los residuos especiales provenientes de establecimientos que realizan actividades relacionadas con el área de la Salud (derogó la Resolución n. 04153 de 1993).

Decreto $N^{\circ} 2676$ (22/12/2000), Por el cual se reglamenta la gestión integral de los residuos hospitalarios y similares.

Resolución $N^{\circ} 4445$ (2/12/1996), Por la cual se dictan normas referentes a las condiciones sanitarias que deben cumplir las Instituciones Prestadoras de servicios de Salud.

Decreto No 3518 (9/10/2006), Por el cual se crea y reglamenta el Sistema de Vigilancia en Salud Pública (SIVIGILA) (derogó el Decreto n. 1562 de 1984).

Ley $N^{\circ} 100$ (23/12/1993), Por la cual se crea el Sistema de Seguridad Social Integral. 
Decreto N 1011 (3/4/2006), Por el cual se establece el Sistema Obligatorio de Garantía en Calidad de la Atención de Salud del Sistema General de Seguridad Social en Salud (SOGCS) (derogó el Decreto n. 2174 de 1996 y el Decreto n. 2309 de 2002).

Ley Estatutaria $N^{\circ} 1751$ (16/02/2015), Por medio de la cual se regula el Derecho Fundamental a la Salud.

Ley N ${ }^{\circ} 1438$ (19/1/2011), Por la cual se reforma el Sistema General de Seguridad Social en Salud.

Resolución No 1446 (8/5/2006), Por la cual se define el sistema de información para la calidad y se adoptan los indicadores de monitoría del Sistema Obligatorio de Garantía de Calidad de la atención en salud.

Francia

Loi $\mathrm{N}^{\circ}$ 2002-303 du 4 mars 2002, relative aux droits des malades et à la qualité du système de santé.

Décret $\mathrm{N}^{\circ}$ 2010-1408 du 12 novembre de 2010, relative à la lutte contre les évènements indésiderables associés aux soins dans les établissements de santé.

Loi N ${ }^{\circ}$ 2002-1577 du 30 décembre 2002, relative à la responsabilité civile médicale.

Circ. Ministre de la solidarité, de la santé et de la protection sociale $\mathrm{N}^{\circ} 88-263,13$ oct. 1988.

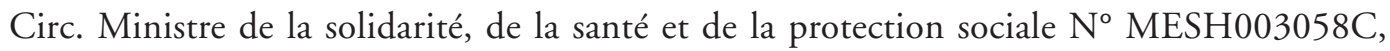
29 déc. 2000 relative à l'organisation de la lutte contre les infections nosocomiales dans les établissements de santé. 